\title{
A Systematic Review on Immunotherapy for Guillain- Barre Syndrome
}

\author{
ANAYEEM $^{\mathrm{a}}$, QD MOHAMMAD $^{\mathrm{b}}$, ZS SUSAN $^{\mathrm{c}}$
}

\begin{abstract}
:
Guillain-Barré syndrome (GBS) is an acute immunemediated polyradiculoneuropathy with a highly variable clinical course and outcome. Intravenous immunoglobulin (IVIG) and plasma exchange (PE) are proven effective treatments, but about half of the patients may not respond to these therapies; moreover, these are not established yet to treat patients of every stage of GBS or its variants. Results from the International Guillain-Barré Syndrome Outcome Study suggest that geographical variations exist in Guillain-Barré syndrome, including insufficient access to immunotherapy in low-income countries. There is a need to provide improved
\end{abstract}

\section{Introduction:}

Guillain-Barré syndrome (GBS) is a rapidly progressive and potentially life-threatening immune-mediated polyradiculoneuropathy that requires early diagnosis, monitoring, and treatment. ${ }^{1,2}$ It accounts for an estimated 100000 new cases annually worldwide. ${ }^{3}$ In Bangladesh, the incidence rate ranges from $1 \cdot 5$ to $2 \cdot 5$ cases per 100000 person-years in adults, and $3 \cdot 25$ in children, ${ }^{4}$ which is higher than that of the developed countries. In most patients $(76 \%)$, the acute onset of neurological symptoms is preceded by an infective illness, ${ }^{5}$ mainly upper respiratory tract infections (35\%) in Europe, North America, and east and southeast Asia whereas gastroenteritis (27\%) in Bangladesh and South America. ${ }^{6}$ Campylobacter jejuni -gastroenteritis was extensively reported ${ }^{7}$ and robust evidence suggests that molecular mimicry exists between nerve and microbial antigens, leading to the development of GBS. ${ }^{8}$

a. Dr. Abu Nayeem, Associate Professor, Neurology, National Institute of Neurosciences and Hospital, Dhaka-1207

b. Professor Quazi Deen Mohammad, Director, National Institute of Neurosciences and Hospital, Dhaka-1207

c. Dr. Zobaida Sultana Susan, Junior Consultant, Gyne and Obs, Deputed at Dhaka medical College and Hospital, Dhaka1000

Address of Correspondence: Dr. Abu Nayeem, Associate Professor, Neurology, National Institute of Neurosciences and Hospital, Dhaka-1207, Email: zara_nym@yahoo.com, Cell: 01711009172 Received:

Accepted: 1 access to treatment for all patients with Guillain-Barré syndrome, and to develop effective disease-modifying therapies that can limit the extent of nerve injury. In this review, the current literature about immunotherapeutic options is highlighted in the context of stages of the disease and its variants and additionally, upcoming modalities are discussed briefly.

Key words: Guillain-Barré syndrome, Immunotherapies for GBS, IVIG, Plasma Exchange.

(J Bangladesh Coll Phys Surg 2022; 40: 57-64)

DOI: https://doi.org/10.3329/jbcps.v40i1.57060

Identifying the trigger for GBS, i.e. 'the antecedent infection' is important to understand the underlying pathogenic mechanisms, but also to anticipate a possible rise in incidence following an epidemic or pandemic, as was seen with the recent Zika virus infection. ${ }^{9,}{ }^{10}$ So far more than $220 \mathrm{GBS}$ cases were reported following current COVID-19 infection, ${ }^{11}$ but actual cases would be much higher, expected to be reported in near future due to longstanding pandemic of COVID-19 infection.

Both the humoral and the cellular immunity are likely to have a crucial role in disease pathogenesis. Autoantibodies against peripheral nerve molecules such as gangliosides or proteins of the Ranvier node have been described. ${ }^{12}$ Accordingly various immunotherapies have been established by this time. Among them, Plasma exchange (PE, usually $200-250 \mathrm{~mL} / \mathrm{kg}$ in five sessions) and intravenous immunoglobulin (IVIG, $0.4 \mathrm{~g} / \mathrm{kg}$ for 5 days) are proven equally effective in shortening time to recovery and improving clinical outcome but not in reducing mortality. ${ }^{13}$

Despite the effective immunotherapies- the outcome in many patients is still poor: $2-10 \%$ may die, $20 \%$ are still unable to walk after 6 months and many patients suffer from residual symptoms, including pain and severe fatigue; ${ }^{14,15}$ moreover, these were tested only with severe forms of GBS patients and very few articles were published with mild forms or with its variants. Finally, these are very costly therapeutic modalities and every patient in developing countries can't avail of these options. 
In this review, the published works of literature were systematically searched to get an idea of different immunotherapies used in various stages of GBS and its variants and also tried to know about the future potential compounds that can be used to treat the patients costeffectively.

\section{Objectives:}

This review will highlight and elaborate on the following issues:

1. Effectiveness of immunotherapies in hastening recovery and reducing the long-term morbidity in the severe form of GBS

2. The window period for initiation of standard immunotherapies (IVIG and PE)

3. The efficacy of immunotherapies in the mild form of GBS, in GBS variants, and children

4. Appropriate dosing of standard immunotherapies

5. Therapeutic modalities in insufficient clinical response and treatment-related fluctuations

6. Future modalities of therapeutic compounds.

\section{Search strategy and selection criteria:}

The articles were searched from the Cochrane Library, PubMed, Medline using the keyword "Guillain-Barré syndrome," "Immunotherapies for GBS," "IVIG" and "Plasma Exchange." Publications from January 2010, to September 2021, were primarily selected, but also included older publications that provided information matched with objectives. Review articles also searched that were relevant to the subject matter.

\section{Plasma exchange (PE):}

Therapeutic plasma exchange has been used in medical conditions for many years, but in the treatment of GBS were reported between 1978 and 1981, with small uncontrolled series claiming clinical benefit. ${ }^{16-20}$ Since these first reports, so far six Randomized Control trials (RCTs) have been conducted and published comparing plasma exchange with supportive treatment alone. ${ }^{21-26}$ All concluded that plasma exchange improved the majority of outcomes compared to supportive care alone.

The clinical efficacy of PE depends on the volume of plasma exchanged, number and frequency of sessions, nature of the replacement solution, and the separating technique. Usually, four exchange is sufficient for therapeutic purposes.

\section{Intravenous immunoglobulin (IVIG):}

Immunoglobulin for therapeutic use is purified from human plasma pooled from at least 1000 donors. IVIG was introduced for the treatment of autoimmune thrombocytopenia ${ }^{27}$ and other autoimmune disorders including chronic inflammatory demyelinating polyradiculoneuropathy ${ }^{28}$ before that use in GBS. Kleyweg $1988^{29}$ reported an apparently favorable response from IVIG in a pilot study in GBS. This led to the first randomized trial comparing IVIG with PE in GBS, which reported that IVIG was possibly superior. ${ }^{30}$ Subsequent trials reviewed have confirmed that IVIG and PE have similar efficacy in every outcome measure. ${ }^{31,32}$ However, IVIG treatment is easier to implement and potentially safer than plasma exchange, and the use of IVIG versus PE may be a choice of availability and convenience. ${ }^{33}$ Additionally, IVIG is the preferential treatment in hemodynamically unstable patients and in those unable to ambulate independently. ${ }^{34}$

Many potential reasons for the beneficial effect of IVIG in autoimmune diseases have been proposed. Possible mechanisms in GBS include blockade of Fc receptors on macrophages and

preventing antibody-mediated complement activation; regulation of autoantibodies or cytokines by antiidiotypic or anti-cytokine antibodies in the pooled immunoglobulin; up-regulation of the inhibitory Fcgamma receptor IIB on B cells; ${ }^{35}$ down-regulation of B cell-activating factor ${ }^{36}$ and interference with the complement cascade or regulatory effects on T cells. ${ }^{37}$ Furthermore, the high concentrations of circulating immunoglobulin accelerate the breakdown of immunoglobulin $\mathrm{G}$ by intracellular lysosomes. ${ }^{38}$

\section{'Mildly VS severely affected' patients:}

A mild form of GBS usually be considered as a patient who is still able to walk unaided, but this patient may have other severe neurological deficits. Up to $38 \%$ of these patients reported problems in hand function and running after 6 months follow-up and only $22 \%$ received treatment. 39

On the other hand, severe form, defined as walking with an aid or worse (table 1$)^{40}$. Most RCTs were conducted 
with this type of patients and the primary endpoint in these trials was usually based on the proportion of patients regaining the capacity to walk unaided or improving by at least one grade on the GBS disability scale.

The Cochrane reviews on PE and IVIG provide no direct advice for the treatment of mild GBS. ${ }^{41}$

However, a small group of children with mild GBS showed a shorter time to improvement and a lower GBS disability grade at 4 weeks in the IVIG group. ${ }^{42}$ One RCT with PE also concluded with a beneficial effect. ${ }^{26}$ But long-term outcome (defined as full muscle strength recovery after 1 year) was not significantly different. Moreover, spontaneous full recovery is possible due to the mild course of the disease, so the therapeutic procedures should be a rethink in the context of cost-effectiveness and risk-benefit analysis. The current recommendation for treating (with IVIG or PE) these patients are having autonomic dysfunctions, bulbar involvement, or facial weakness.

\section{Table-I}

\section{Guillain-Barré syndrome (GBS) disability scale}

Grade

0 Healthy

1 Minor symptom and capable of running

2 Able to walk $10 \mathrm{~m}$ without assistance but unable to run

3 Able to walk $10 \mathrm{~m}$ across an open space with the help

4 Bedridden or chair bound

5 Requiring assisted ventilation for at least part of the day

6 Dead

\section{Adapted from: Hughes et al, ${ }^{41}$}

Therapeutic window period: Short VS Long

Most of the RCTs with IVIG and PE in GBS were conducted in the acute phase of the disease, within 2 (in case of IVIG) to 4 weeks (in case of PE) after the onset of weakness. But it may be assumed that treatment is most effective when started as soon as possible to prevent further nerve damage, similar to the concept 'Time is brain' in ischaemic Stroke. Some support for this hypothesis comes from the PE trials, where PE in patients randomized within 7 days had more favorable effects than in patients randomized between 8 and 28 days after onset. ${ }^{41}$ Furthermore, IVIG has pleiotropic immune-modulatory effects, may prevent ongoing nerve damage when initiated early. ${ }^{41}$ Based on these, the recent recommendation is, to start treatment as soon as possible in patients who walk with aid, are bedbound, or are ventilated. In patients who are still able to walk unaided but show rapid progression of symptoms should not wait for further clinical deterioration.

The progression of the disease takes $<4$ weeks, and most patients will present within a few

days to weeks after the onset of symptoms. ${ }^{43}$ For this reason immunotherapies were best studied within this period. However, about $3 \%$ of patients may progress during 4-8 weeks that may be due to an ongoing immune-mediated injury of the nerves (subacute idiopathic demyelinating polyneuropathy, SIDP) ${ }^{44}$ For these cases, no evidence is available regarding the treatment effect of IVIG or PE. But when progression persists after 8 weeks, chronic inflammatory demyelinating polyneuropathy (CIDP) should be considered and then (re-) treatment with IVIG or even a switch to corticosteroids is indicated. ${ }^{45}$

\section{Best effective doses:}

The standard dose of IVIG is $0.4 \mathrm{~g} / \mathrm{kg}$ per day for five days. The infusion is typically started slowly $(0.3$ to $0.5 \mathrm{~mL} / \mathrm{kg} /$ hour depending on formulation) and increased every 15 to 30 minutes as tolerated up to 6 to $8 \mathrm{~mL} / \mathrm{kg}$ /hour. The infusion is held or the rate reduced to address adverse effects.

One trial compared $0.4 \mathrm{~g} / \mathrm{kg}$ of IVIGdaily for three days with the same dose daily for six days. ${ }^{46}$ The results showed a trend in favor of the higher dose. Another trial compared $1.0 \mathrm{~g} / \mathrm{kg}$ daily for two days with the standard regimen of $0.4 \mathrm{~g} / \mathrm{kg}$ daily for five days, giving the same total dose to each. ${ }^{47}$ There were no significant differences in the primary or secondary outcome measures reported by the authors except that early relapses were significantly more common after the twoday than the five-day regimen.

In a PE trial with moderately severe GBS, those who received four exchanges showed quicker improvement than those who received two. ${ }^{26}$ However, six exchanges were not superior to four. For patients with severe disease requiring mechanical ventilation who received six exchanges, there was a non-significant trend toward reduced time on mechanical ventilation compared with those who received four and the rate of full strength at one year was not improved. ${ }^{26}$ 


\section{Therapeutic complications: ${ }^{48}$}

In the IVIG group, Adverse effects include hypotension, nausea, headache with or without aseptic meningitis, rash, acute kidney failure (mostly related to sucrosecontaining products), and transfusion reactions. Rarely, patients may develop hyperviscosity leading to stroke or myocardial infarction. IgA deficiency can lead to anaphylaxis; however, patients without IgA deficiency can also develop hypersensitivity reactions to IVIG, especially when exposed to different formulations.

The main complications in the plasma exchange group are hypotension, sepsis, transfusion reactions, and problems with intravenous access not suitable for hemodynamically unstable patients

Insufficient clinical response after initial treatment: At present, it is not always possible to evaluate the effect of treatment on a clinical basis. Previous trials have shown that about $40-50 \%$ of patients treated with either PE or IVIG show no improvement on the GBS disability scale at 4 weeks. ${ }^{30}$ In that condition, whether a patient would benefit from a second course or a change to another treatment cannot be determined yet.

a) Switch to another therapy

Some neurologists may switch to the other treatment after either IVIG or PE as initial treatment if there is no clinical response. The rationale is that these treatments probably have different immunomodulatory effects that may influence the treatment efficacy in individual patients.

One randomized trial compared the efficacy of PE followed by IVIG, and PE alone in 379 severely affected patients but did not find significant differences between the treatment modalities in any of the outcome measures. ${ }^{50}$ Another small retrospective study in 46 patients reported that treatment with IVIG followed by PE was not better than IVIG alone. Moreover, the patients who received both treatments had a worse GBS disability grade at discharge and were being longer hospitalised. ${ }^{51}$

\section{b) Retreatment}

Another option is to repeat the same regimen of treatment, being either PE or IVIG. For patients treated initially with PE with no improvement or further deterioration, retreating (no more than one time)with PE may be attempted at two weeks after initial treatment was begun, under close observation for side effects. ${ }^{48}$

For those treated initially with IVIG, retreating with IVIG was not recommended because it exposes patients to adverse risks without additional benefit. In a trial of 93 patients with acute GBS who were treated with an initial course of IVIG, patients with a predicted poor outcome were randomized to the second round of IVIG or placebo beginning within 9 days of the start of the first treatment. ${ }^{52}$ At four-week follow-up, those assigned to the second round of IVIG treatment had similar disability scores and more adverse effects ( 17 versus 7 ) compared with those who received placebo.

\section{Treatment-related fluctuation (TRF):}

TRF is generally defined as a worsening of at least one grade on the GBS disability scale, or a decrease in Medical Research Council sum score after initial stabilization or improvement within the first 8 weeks after treatment. ${ }^{53}$ TRFs have been reported in $8-16 \%$ of patients with GBS treated with either IVIG or PE. ${ }^{54} \mathrm{At}$ present it is not possible to predict who may develop a TRF or how long and severe a TRF will be.

The mechanism of a TRF has not been elucidated but it has been hypothesized that the effect of treatment is transient while disease activity continues. ${ }^{54}$ Therefore, it is rational to treat a patient with a TRF with the second course of either IVIG or PE but no RCTs have been conducted to demonstrate the effect.

\section{Add-on or alternative treatment:}

Various trials have shown, treatment with corticosteroids alone does not improve recovery in GBS and some studies even suggest that oral corticosteroids may delay recovery. ${ }^{55}$ One large RCT indicated that intravenous methylprednisolone $(500 \mathrm{mg}$ /day for 5 days), when added to IVIG, has a small effect at 4 weeks after a posthoc correction for known prognostic factors, but there was no improvement of long-term outcome. ${ }^{56}$

Two small RCTs have reported a non-significant effect of brain-derived neurotrophic factor (BDNF) or interferon â-1a (IFNâ-1a) on disability grade or rate of improvement, respectively. ${ }^{5758} \mathrm{~A}$ third small RCT found a significant effect on the improvement of disability grade 8 weeks after the onset of symptoms when patients were treated with a Chinese herbal medicine tripterygium polyglycoside compared with high-dose corticosteroids. ${ }^{59}$ Another small, open parallel-group study found a similar effect when comparing PE to filtration of cerebrospinal fluid. ${ }^{60}$ In critically ill patients, a small German study reported that treatment with selective immune adsorption (SIA) seemed to be safe and effective. ${ }^{61}$ But these studies were too small to exclude clinical relevance and larger sequential RCTs might be more promising. ${ }^{62}$ At present there is no evidence for the effect of alternative treatments. 


\section{GBS in children:}

GBS may occur at all ages. Currently, there is no indication to treat children with GBS differently than adults. Various studies showed that IVIG had a significant effect on shortening the time to improvement and total recovery than dexamethasone or supportive care. ${ }^{63}$ The effect of PE has not been investigated extensively in large randomized trials in children. PE in children can have more adverse events and complications than in adults because of citrate toxicity, higher relative vascular volume shifts, and the need for safe vascular access. ${ }^{64}$

\section{Patients with variant forms of GBS:}

The efficacy of immunotherapy for patients with variants form of GBS has not been firmly established. In Miller Fisher variant, immunotherapy may be considered for those who have respiratory involvement and those whose symptoms evolve to include bulbar or limb weakness. ${ }^{65}$ For patients with Bickerstaff brainstem encephalitis, immunotherapy can be offered because of the severity of symptoms, despite lack of evidence of the efficacy. ${ }^{66}$

\section{Future compounds:}

Studies in patients and animal models have established the crucial role of complement activation in the pathogenesis of GBS. ${ }^{67}$ Eculizumab (Figure 1:3), a humanized monoclonal recombinant antibody to complement factor 5, prevents the formation of membrane attack complex and nerve injury in an animal model for GBS. ${ }^{68}$ This complement inhibitor is therefore a promising new treatment for GBS that is currently being investigated in two RCTs (Inhibition of Complement Activation (Eculizumab) in GBS study (ICA-GBS) in UK and Japanese Eculizumab Trial for GBS (JET-GBS) in Japan). ${ }^{69,70}$ These studies implicate that eculizumab seems safe and well-tolerated, and might potentially improve outcome in GBS as an add-on treatment to IVIG, but larger trials should be required.

Another complement inhibitor that was shown effective in mouse models is an anti-complement factor $1(\mathrm{C} 1) \mathrm{q}$ antibody (Figure 1:2). Currently, a phase 1 clinical trial to assess safety and tolerability of anti-C1q antibody (ANX005) in healthy volunteers is being conducted. ${ }^{72}$

Another potentially promising therapeutic agent is the IgG-degrading enzyme that is secreted

by Streptococcus pyogenes (IdeS). The enzyme cleaves IgG molecules into the antigen-binding fragment $\mathrm{F}(\mathrm{ab}) 2$ - and Fc-portion, and is therefore expected to be effective in GBS through the cleavage of pathogenic antibodies (Figure 1: 1) ${ }^{72}$. A phase 2 trial for IdeS is planned in Europe.

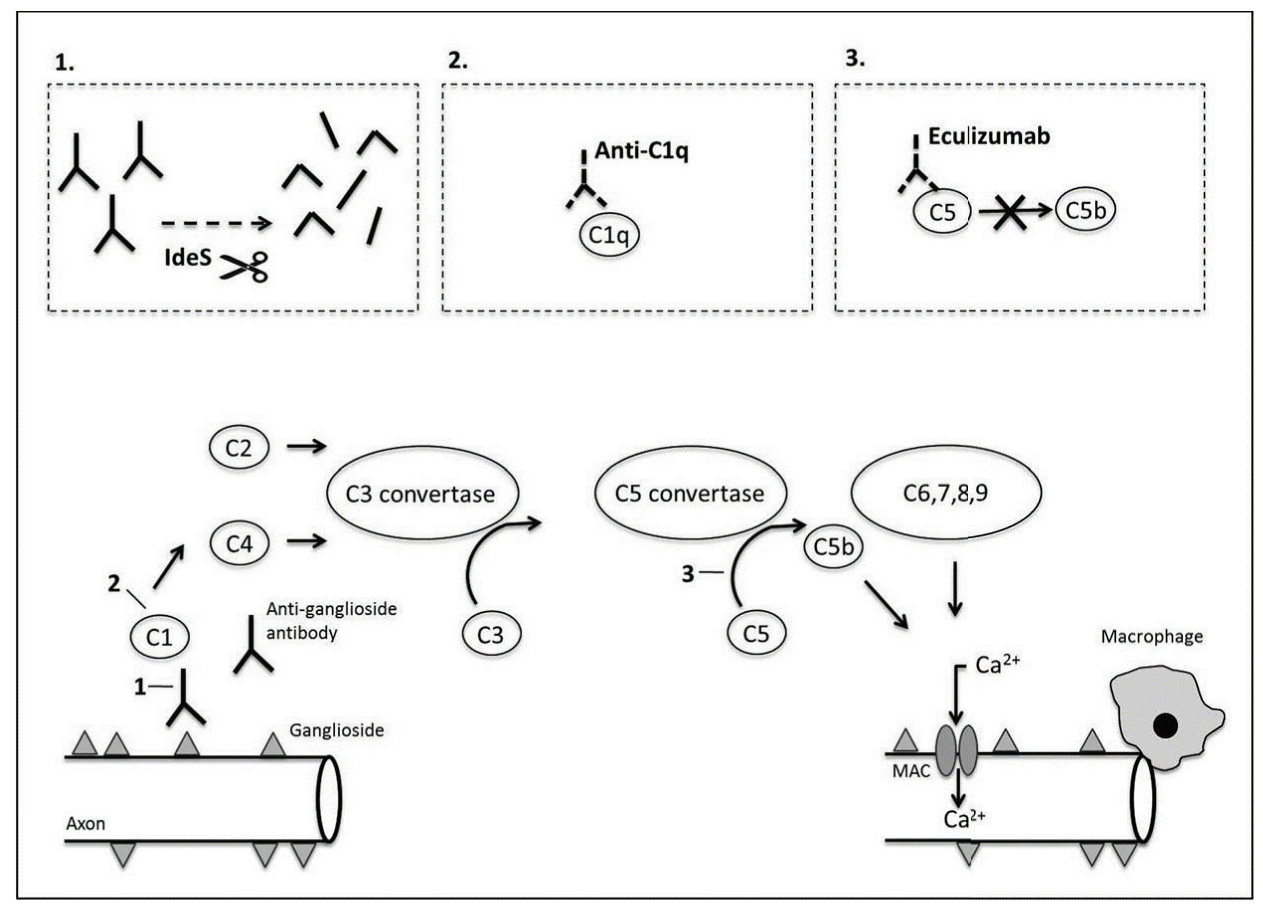

Fig.-1: future therapeutic molecules ${ }^{75}$ 
Furthermore, reports of in vitro and animal studies and case reports on the efficacy of biological drugs in GBS show promising results, but clinical trials are needed to extent these findings ${ }^{73}$.

\section{For the patients from developing countries:}

Guillain-Barré syndrome (GBS) takes its toll on the resource-poor developing countries where the incidence of GBS is severalfold higher than that of Europe and North America. The poor outcome of GBS in these countries is explained predominantly by the lack of treatment and medical support. More than $90 \%$ of patients receive only supportive care. Small volume plasma exchange (SVPE) can be the most affordable alternative for these patients. It is based on the same principle as $\mathrm{PE}$, where neurotoxic antibodies containing plasma and other components are separated from the patients' blood by gravity, which is 25 times less expensive. One pilot study in Bangladesh showed its effectiveness. ${ }^{74}$ But a well-designed larger study should be conducted. If the efficacy is demonstrated, SVPE will be the best option for patients from low-income countries. About more than half of all patients with GBS in the world belong to this category.

\section{Conclusion:}

GBS is clinically and immunopathologically a heterogeneous disorder in which very few effective (and unspecific) immunomodulatory therapies are available. Biomarkers for treatment selection and monitoring are lacking, that resulting in under-treatment, treatment failure,

and suboptimal outcomes. Further researches are warranted for the development of specific molecules to combat the disease appropriately in a cost-effective way.

\section{References:}

1. van den Berg B, Walgaard C, Drenthen J, et al. GuillainBarré syndrome:pathogenesis, diagnosis, treatment and prognosis. Nat Rev Neurol 2014; 10:469-82.

2. Willison HJ, Jacobs BC, van Doorn PA. Guillain-Barré syndrome. Lancet 2016; 388:717-27.

3. Sejvar JJ, Baughman AL, Wise M, Morgan OW. Population incidence of Guillain-Barré syndrome: a systematic review and meta-analysis. Neuroepidemiology 2011; 36: 123-33.

4. Islam Z, Jacobs BC, Islam MB, Mohammad QD, Diorditsa S, Endtz HP. High incidence of Guillain-Barre syndrome in children, Bangladesh. Emerg Infect Dis 2011; 17: 1317-18.
5. Jacobs BC, Rothbarth PH, van der Meché FG, et al. The spectrum of antecedent infections in Guillain-Barré syndrome: a case-control study. Neurology 1998; 51: 1110-15.

6. Doets AY, Verboon C, van den Berg B, et al. Regional variation of Guillain-Barré syndrome. Brain 2018; 141: 2866-77.

7. Wachira VK, Peixoto HM, de Oliveira MRF. Systematic review of factors associated with the development of Guillain-Barré syndrome 2007-2017: what has changed? Trop Med Int Health 2019; 24: 132-42.

8. Yuki N, Susuki K, Koga M, et al. Carbohydrate mimicry between human ganglioside GM1 and Campylobacter jejuni lipooligosaccharide causes Guillain-Barre syndrome. Proc Natl Acad Sci USA 2004; 101: 11404-09.

9. Cao-Lormeau VM, Blake A, Mons S, et al. Guillain-Barre' syndrome outbreak associated with Zika virus infection in French Polynesia: a case-control study.Lancet 2016; 387:1531-1539.

10. Parra B, Lizarazo J, Jimenez-Arango JA, et al. GuillainBarre syndrome associated with Zika virus infection in Colombia. N Engl J Med 2016; 375:1513-1523.

11. Khan F, Sharma P, Pandey S, et al. COVID 19 associated Guillain Barre syndrome: Postinfectious alone or neuroinvasive too? J Med Virol 2021; 93:6045 6049. Doi: $10.1002 / j m v .27159$

12. Schafflick D, Kieseier BC, Wiendl H, Meyer zu Horste G. Novel pathomechanisms in inflammatory neuropathies. $J$. Neuroinflammation 2017; 14(1):1-17 https:// doi. org/ 10.1186/ s12974- 017- 1001-8.

13. Ortiz-Salas P, Velez-Van-Meerbeke A, Galvis-Gomez CA, Rodriguez QJ. H. Human immunoglobulin versus plasmapheresis in Guillain-Barre syndrome and myasthenia gravis: A meta-analysis. J. Clin. Neuromuscul. Dis. 2016; $18: 1-11$.

14. van den Berg B, Bunschoten C, van Doorn PA, et al. Mortality in Guillain-Barre syndrome. Neurology 2013; $80: 1650-4$.

15. Ruts L, Drenthen J, Jongen JL, et al. Pain in Guillain-Barre syndrome: a long-term follow-up study. Neurology 2010; 75:1439-47.

16. Brettle_RP, Gross_M, Legg_NJ, Lockwood_M, Pallis_C. Treatment of acute polyneuropathy by plasma exchange. Lancet 1978; 2(8099):1100.

17. Mark_B, Hurwitz_J, Olanow_CW, Fay_JW. Plasmapheresis in idiopathic inflammatory polyradiculoneuropathy. Neurology 1980; 30(4):361.

18. Ropper_AH, Shahani_B, Huggins_CE. Improvement in four patients with acute Guillain-Barré syndrome aDer plasma exchange. Neurology 1980; 30:361.

19. Schooneman_F, Janot_C, StreiL_F, Gérard_A, Dureux_JB, Canton_P,et al. Plasma exchange in Guillain-Barré 
syndrome ten cases. Plasmapheresis Therapy 1981; 2:117-21.

20. Valbonesi_M, Garelli_S, Mosconi_L, Zerbi_D, Celano_I. Plasma exchange as a therapy for Guillain-Barré syndrome with immune complexes. Vox Sanguinis 1981; 41:74-8.

21. Farkkila_M, Penttila_P. Plasma exchange therapy reduces the nursing care needed in Guillain-Barré syndrome. Journal of Advanced Nursing 1992; 17(6):672-5.

22. Greenwood_RJ, Newsom-Davis_J, Hughes_RAC, Aslan_S, Bowden_AN, Chadwick_DW, et al. Controlled trial of plasma exchange in acute inflammatory polyradiculoneuropathy. Lancet 1984; 1(8382):877-9. [PUBMED: 6143188]

23. The Guillain-Barré syndrome study group. Plasmapheresis and acute Guillain-Barré syndrome. Neurology 1985; 35(8):1096-104. [PUBMED: 4022342]

24. Osterman_PO, Fagius_J, Lundemo_G, Pihlstedt_P, Pirskanen_R, Siden_A, et al. Beneficial effects of plasma exchange in acute inflammatory polyradiculoneuropathy. Lancet 1984; 2(8415): 1296-9. [PUBMED: 6150321]

25. French Cooperative Group on Plasma Exchange in GuillainBarré syndrome. Efficiency of plasma exchange in GuillainBarré syndrome: role of replacement fluids. Annals of Neurology 1987; 22(6):753-61. [PUBMED: 2893583]

26. French Cooperative Group on Plasma Exchange in GuillainBarré Syndrome. Appropriate number of plasma exchanges in Guillain-Barré Syndrome. Annals of Neurology 1997; 41(3):298-306. [PUBMED: 9066350]

27. Imbach P, Barandun S, d'Apuzzo V, Baumgartner C, Hirt A, Morell A, et al. High dose intravenous gammaglobulin for idiopathic thrombocytopenic purpura. Lancet 1981; 1(8232): 1228-31.

28. Vermeulen M, van der Meché_FGA, Speelman JD, Weber A, Busch HFM. Plasma and gammaglobulin infusion in chronic inflammatory polyneuropathy. Journal of the Neurological Sciences 1985; 70(3):317-26.

29. Kleyweg RP, van der Meché FGA, Meulstee J. Treatment of Guillain-Barré syndrome with high dose gammaglobulin. Neurology 1988; 38(10):1639-41.

30. van der Meché FGA, Schmitz PIM, Dutch Guillain-Barré Study Group. A randomized trial comparing intravenous immune globulin and plasma exchange in Guillain-Barré syndrome. New England Journal of Medicine 1992; 326(17):1123-9. [PUBMED:1552913]

31. Hadden RD, Cornblath DR, Hughes RA, Zielasek J, Hartung HP, Toyka KV, et al. Electrophysiological classification of Guillain-Barré syndrome: clinical associations and outcome. Plasma Exchange/Sandoglobulin Guillain-Barré Syndrome Trial Group. Ann Neurol 1998; 44(5):780-8.

32. Bascic-Kes V, Kes P, Zavoreo I, Lisak M, Zadro L, Coric L, et al. Guidelines for the use of intravenous immunoglobulin in the treatment of neurologic diseases. Acta Clin Croat 2012; 51(4):673-83.

33. Hughes RA, Wijdicks EF, Barohn R, Benson E, Cornblath DR, Hahn AF, et al. Practice parameter: immunotherapy for Guillain-Barré syndrome: report of the Quality Standards Subcommittee of the American Academy of Neurology. Neurology 2003; 61(6):736-40.

34. Lindenbaum Y, Kissel JT, Mendell JR. Treatment approaches for Guillain-Barré syndrome and chronic inflammatory demyelinating polyradiculoneuropathy. Neurol Clin 2001; 19(1):187-204.

35. Tackenberg B, Jelcic I, Baerenwaldt A, Oertel WH, Sommer N, Nimmerjahn_F, et al. Impaired inhibitory Fcgamma receptor IIB expression on B cells in chronic inflammatory demyelinating polyneuropathy. Proceedings of the National Academy of Sciences of the United States of America 2009; 106(12):4788-92.

36. Bick S, Tschernatsch M, Karg A, Fuehlhuber V, Trenczek $\mathrm{TE}$, Faltermeier $\mathrm{K}$, et al. Intravenous immunoglobulin inhibits BAFF production in chronic inflammatory demyelinating polyneuropathy - a new mechanism of action?. Journal of Neuroimmunology 2013; 256(1-2):8490 .

37. Dalakas MC. The use of intravenous immunoglobulin in the treatment of autoimmune neuromuscular diseases: evidence-based indications and safety profile. Pharmacology \& Therapeutics 2004; 102(3):177-93.

38. Yu Z, Lennon VA. Mechanism of intravenous immune globulin therapy in antibody-mediated autoimmune diseases. New England Journal of Medicine 1999; 340(3):227-8.

39. Van Koningsveld R, Schmitz PI, Ang CW, et al. Infections and course of disease in mild forms of Guillain-Barré syndrome. Neurology 2002; 58:610-14.

40. Hughes RA, Newsom-Davis JM, Perkin GD, et al. Controlled trial prednisolone in acute polyneuropathy. Lancet 1978; 2:750-3.

41. Hughes RA, Swan AV, van Doorn PA. Intravenous immunoglobulin for Guillain-Barré syndrome. Cochrane Database Syst Rev 2014(9):CD002063.

42. Korinthenberg R, Schessl J, Kirschner J, et al. Intravenously administered immunoglobulin in the treatment of childhood Guillain-Barré syndrome: a randomized trial. Pediatrics 2005; 116:8-14.

43. Fokke C, van den Berg B, Drenthen J, et al. Diagnosis of Guillain-Barré syndrome and validation of Brighton criteria. Brain 2014; 137:33-43.

44. Hughes R, Sanders E, Hall S, et al. Subacute idiopathic demyelinating polyradiculoneuropathy. Arch Neurol 1992; 49:612-16.

45. Eftimov F, Winer JB, Vermeulen M, et al. Intravenous immunoglobulin for chronic inflammatory demyelinating 
polyradiculoneuropathy. Cochrane Database Syst Rev 2013(12):CD001797.

46. Raphael_J-C, Chevret_S, Harboun_M, Jars-Guincestre_MC,French Guillain-Barré syndrome Study Group. Intravenous immune globulins in patients with Guillain-Barré syndrome and contraindications to plasma exchange: 3 days versus 6 days. Journal of Neurology, Neurosurgery and Psychiatry 2001; 71(2):235-8. [PUBMED: 11459901]

47. Korinthenberg_R, Schessl_J, Kirschner_J, Monting_JS. Intravenously administered immunoglobulin in the treatment of childhood Guillain-Barré syndrome: a randomized trial. Pediatrics 2005; 116(1):8-14. [PUBMED: 15995024]

48. https://www.uptodate.com/contents/guillain-barresyndrome-in-adults-treatment-and-prognosis? source $=$ history_widget\#H1

50. Randomised trial of plasma exchange, intravenous immunoglobulin, and combined treatments in Guillain-Barre syndrome. Plasma Exchange/Sandoglobulin Guillain-Barré Syndrome Trial Group. Lancet 1997; 349:225-30.

51. Oczko-Walker M, Manousakis G, Wang S, et al. Plasma exchange after initial intravenous immunoglobulin treatment in Guillain-Barré syndrome: critical reassessment of effectiveness and cost-efficiency. J Clin Neuromuscul Dis $2010 ; 12: 55-61$.

52. Walgaard C, Jacobs BC, Lingsma HF, et al. Second intravenous immunoglobulin dose inpatients with GuillainBarré syndrome with poor prognosis (SID-GBS): a doubleblind, randomised, placebo-controlled trial. Lancet Neurol 2021; 20:275.

53. Kleyweg RP, van der Meché FG. Treatment related fluctuations in Guillain-Barré syndrome after high-dose immunoglobulins or plasma-exchange. J Neurol Neurosurg Psychiatr 1991; 54:957-60.

54. Ruts L, Drenthen J, Jacobs BC, et al. Distinguishing acuteonset CIDP from fluctuating Guillain-Barre syndrome: a prospective study. Neurology 2010; 74:1680-6.

55. Hughes RA, van Doorn PA. Corticosteroids for GuillainBarré syndrome. Cochrane Database Syst Rev 2012; (8):CD001446.

56. van Koningsveld R, Schmitz PI, Meché FG, et al. Effect of methylprednisolone when added to standard treatment with intravenous immunoglobulin for Guillain-Barré syndrome: randomised trial. Lancet 2004; 363:192-6.

57. Bensa S, Hadden RD, Hahn A, et al. Randomized controlled trial of brain-derived neurotrophic factor in Guillain-Barré syndrome: a pilot study. Eur J Neurol 2000;7:423-6.

58. Pritchard J, Gray IA, Idrissova ZR, et al. A randomized controlled trial of recombinant interferon-beta $1 \mathrm{a}$ in Guillain-Barré syndrome. Neurology 2003;61:1282-4.

59. Zhang X, Xia J, Ye H. Effect of Tripterygium polyglycoside on interleukin-6 in patients with Guillain-Barre syndrome.
Zhongguo Zhong Xi Yi Jie He Za Zhi 2000; 20:332-4.

60. Wollinsky KH, Hülser PJ, Brinkmeier H, et al. CSF filtration is an effective treatment of Guillain-Barré syndrome: a randomized clinical trial. Neurology 2001; 57:774-80.

61. Galldiks N, Dohmen C, Neveling M, Fink GR, Haupt WF. Selective immune adsorption treatment of severe Guillain Barré syndrome in the intensive care unit. Neurocrit Care. 2009; 11(3):317-21.

62. Hughes RA, Pritchard J, Hadden RD. Pharmacological treatment other than orticosteroids, intravenous immunoglobulin and plasma exchange for Guillain-Barre syndrome. Cochrane Database Syst Rev 2013;(2):CD008630.

63. Wang R, Feng A, Sun W, et al. Intravenous immunoglobulin therapy in children with Guillain-Barré syndrome. J Applied Clinical Pediatrics 2001; 16:223-4.

64. Michon B, Moghrabi A, Winikoff R, et al. Complications of apheresis in children. Transfusion 2007; 47:1837-42.

65. Sekiguchi Y, Mori M, Misawa S, et al. How often and when Fisher syndrome is overlapped by Guillain-Barré syndrome or Bickerstaff brainstem encephalitis? Eur J Neurol 2016; 23:1058

66. Odaka M, Yuki N, Yamada M, et al. Bickerstaff's brainstem encephalitis: clinical features of62 cases and a subgroup associated with Guillain-Barré syndrome. Brain 2003; 126:2279.

67. Plomp JJ, Willison HJ. Pathophysiological actions of neuropathy-related anti-ganglioside antibodies at the neuromuscular junction. J Physiol 2009; 587: 3979-99.

68. Halstead SK, Zitman FM, Humphreys PD, et al. Eculizumab prevents anti-ganglioside antibody-mediated neuropathy in a murine model. Brain 2008; 131:1197-208.

69. https://clinicaltrials.gov/ct2/show/NCT02493725? term=guillain + barre + AND +eculizumab $\&$ rank $=2$

70. https://clinicaltrials.gov/ct2/show/NCT02029378?term= eculizumab+guillain\% 5 C\&rank $=1$

71. NCT03010046. Single Dose Study of ANX005 in Healthy Volunteers Available from: www.clinicaltrials.gov.

72. Takahashi R, Yuki N. Streptococcal IdeS: therapeutic potential for Guillain- Barre syndrome. Sci Rep 2015; 5:10809.

73. Motamed-Gorji N, Matin N, Tabatabaie O, et al. Biological drugs in Guillain-Barre syndrome: an update. Curr Neuropharmacol 2017; 15:938-950.

74. 148 Islam B, Islam Z, Rahman S, et al. Small volume plasma exchange for Guillain-Barré syndrome in resource-limited settings: a phase II safety and feasibility study. BMJ Open 2018; 8: e022862.

75. Doets AY, Jacobs BC, van Doorn PA. Advances in management of Guillain-Barre syndrome. Curr Opin Neurol 2018; 31:541-550 